\title{
THE INFLUENCE OF LEVEL OF PROFICIENCY IN THE L2 AND L3 ON THE PRODUCTION OF THE L3 SPANISH APICO-ALVEOLAR SIBILANT
}

\author{
JOLANTA SYPIAŃSKA \\ Koszalin University of Technology, Poland \\ jolanta.sypianska@gmail.com
}

ZUZANNA CAL

Adam Mickiewicz University, Poland

\begin{abstract}
Current Third Language Acquisition research has traditionally focused on the L2 status (e.g. Hammarberg 2001, Bardel \& Falk 2007) or linguistic proximity (e.g. Cenoz 2001, Westergaard, Mitrofanova, Mykhaylyk \& Rodina 2016). Limited research has been conducted on the influence of the potentially significant factor of level of proficiency, and particularly where proficiency in both the L2 (Tremblay 2006, Woll 2016) and the L3 (Hammarberg 2001, Wrembel 2010) may be considered as a conditioning factor for the shape of the L3. The aim of the current study was thus to determine the influence of L2 and L3 level of proficiency (L2LoP and L3LoP) and the interaction of the two factors on the production of the L3 Spanish apico-alveolar sibilant in a group of L1 Polish, L2 English and L3 Spanish trilinguals who had different levels of overall proficiency in the two foreign languages. The parameters of the sibilant under analysis were spectral moments: centre of gravity (M1), standard deviation (M2), skewness (M3) and kurtosis (M4) in intervocalic position in two-syllable words with initial stress. The results point to the influential role of both L2LoP and L3LoP as well as their interaction on the production of the L3 Spanish sibilant. When the level of proficiency in one of the languages was low, it allowed the other language with a higher level of proficiency to exert influence on the values of the spectral moments in the L3 sibilant. This interplay of factors furthers the understanding of how levels of proficiency in the L2 and the L3 condition the developing L3.
\end{abstract}

Keywords: phonetics, linguistic proximity, language pedagogy, interference

\section{Introduction}

The possible role of level of proficiency (LoP) has not been widely investigated in the context of Third Language Acquisition (TLA). Even though there are some studies that examine the role of proficiency levels in the L2 (Tremblay 2006, Woll 
2016) and the L3 (Hammarberg 2001, Wrembel 2010) on the acquisition of the third language, there is still insufficient data to determine how these factors contribute to the development of the L3. Thus, the aim of the current study is to analyse the influence of L2 and L3 levels of proficiency and how they impact the production of the L3 Spanish apico-alveolar sibilant. The research group consists of trilingual speakers of L1 Polish, L2 English and L3 Spanish. The participants have different levels of overall proficiency in the two foreign languages with three levels of L2LoP and three levels of L3LoP corresponding to B1, B2 and C1 according to the Common European Framework of Reference (CEFR). The study is focused on the analysis of four spectral moments of the L3 Spanish sibilant including centre of gravity (M1), standard deviation (M2), skewness (M3) and kurtosis (M4) measured in intervocalic position in two-syllable words with initial stress.

Spectral properties of sibilants are then described with particular reference to the Spanish apico-alveolar, including differences in the spectral properties between the apico-alveolar and the lamino-alveolar sibilant. Finally, we present the methodology of the study followed by a discussion of the main findings.

\section{TLA}

Third language acquisition (TLA) is the process of acquiring a second foreign language. Despite being undoubtedly related to second language acquisition (SLA), this process involves a broader set of factors resulting from the mutual influence that takes place between three languages in the speaker's mind. Research in this field concentrates mainly on establishing possible sources of cross-linguistic influence (CLI) that might shape the developing L3. The language a learner predominantly relies on while producing the third language has been shown to depend on certain factors that include the L2 status, typology and psychotypology of languages, linguistic proximity and also level of proficiency.

The first of the factors, "the foreign language effect" (Meisel 1983), later referred to as the L2 status factor (Hammarberg 2001, Bardel \& Falk 2007, 2012), assumes that the second language constitutes the main source of CLI in the third language because there are more similarities between the L2 and the L3 than between the third language and the native one. This factor was shown to play an important role in determining the sources of influence on the $\mathrm{L} 3$ in a great number of studies (e.g. Llama, Cardoso and Collins 2010; Wrembel 2010; Lipińska 2015). On the contrary, Flynn, Foley and Vinnitskaya (2004), in their Cumulative Enhancement Model (CEM), hypothesise that CLI might stem from all languages previously acquired by the speaker. Furthermore, according to the authors, previous language knowledge can only enhance the process of L3 acquisition.

Language distance is also considered to play an important role in determining the possible sources of CLI in the L3. This factor is related to both the typology and psychotypology of languages. The former refers to the actual 
relation between languages which is taken into account in the Typological Primacy Model (TPM) (Rothman 2010, 2013); the latter is understood as perceived language distance (Kellerman 1977), where the influence might originate from the language that is considered to bear the greatest similarity to the target one. The similarities between languages that are not necessarily connected to typology were taken into account in the Linguistic Proximity Model (LPM) (Mykhaylyk et al. 2015; Westergaard et al. 2016). According to this assumption, "the similarity of abstract linguistic properties is the main cause of CLI from previously learned languages" (Westergaard et al. 2016:12) and might have both a facilitative and a non-facilitative influence on the development of the L3. Moreover, this model postulates that cross-linguistic transfer occurs property-byproperty and is not holistic as was postulated by Rothman in TPM.

Most recently, Slabakova (2016) in her Scalpel Model argues that transfer can take place from both L1 and L2 and the learner uses their L1 or L2 grammars with a so-called scalpel-like precision to extract facilitative options for L3 acquisition. Similarly to LPM, the model follows the idea of transfer being favoured by structural linguistic similarities and proposes that it might depend on various other factors, such as construction frequency, or processing complexity among others, which therefore may lead to negative influence on the L3. However, these models, like those mentioned above, pertain only to syntactic transfer rather than phonological influence and the research on whether they can be applied to L3 phonology is scant.

\subsection{Level of proficiency as a conditioning factor}

Current models of TLA take into consideration only certain factors. L2 status, language typology, or linguistic proximity. However, there is no model that concerns the level of proficiency (LoP) in the L2 and L3 as a conditioning factor while determining the sources of CLI in the L3. Still, it is presumed that this factor might govern the amount of influence from other languages in the speaker's linguistic repertoire on the L3.

It is generally assumed that low proficiency in a target language will bring about more influence from a source language. It is because of the existing gaps in the knowledge of a low-proficient speaker that need to be filled in by the already existing knowledge (e.g. Ringbom 1986, Williams and Hammarberg 1998). However, CLI can also occur at more advanced levels of proficiency, but in such cases, as noted by Odlin (1989), it tends to have a rather facilitative impact on the production in a target language.

So far, there has been a paucity of research focusing directly on LoP in the L2 and L3 as factors that condition the process of TLA and possible influences between languages. The focus of the researchers examining the level of proficiency seems to have been mostly on whether or not and to what extent LoP facilitates the acquisition of the L3 (e.g. Simon, Escudero \& Broersma 2010; Garcia 2013), rather than how it affects the possible influence between languages. Moreover, LoP as a factor may be studied within two different approaches, not 
only from the point of view of proficiency in the second but also the third language. As far as L2 proficiency is concerned, it was shown by Hammarberg (2001) that higher competence of the L2 that was used and acquired in natural settings elevates the influence of this language on the L3. Yet, with the advancement of the L3, the L2 influence diminished in favour of the L1. A similar conclusion was proposed by Tremblay (2006) who examined how L1 English and L2 French influence L3 German lexicon when participants varied in terms of level of proficiency and level of exposure in their second language. It was established that only subjects with high proficiency in their L2 and high exposure to this language experienced the greatest amount of influence from the L2 on the third language.

With regards to LoP in the target language, it is generally assumed that the lower the proficiency in the third language, the more there is influence from the L2 (e.g. Gut 2010; Sánchez 2014). In the study by Sánchez (2014), who analysed verb placement in L3 learners of English, the second language appeared to considerably influence the third one, but only up to a certain L3LoP, which was estimated as intermediate by the author. After this level, the participants were able to inhibit the activation of the L2. What is more, Wrembel (2010) in her study on cross-linguistic influence in L1 Polish, L2 German, L3 English speakers showed that with sufficiently high L3 proficiency it was the native language that was activated in the participants' speech.

Sypiańska (2017), on the other hand, analysed the role of level of proficiency in a group of L1 Polish, L2 Danish and L3 English speakers. The parameter under investigation was VOT in the initial $/ \mathrm{p}, \mathrm{t}, \mathrm{k} /$ of the languages in the speakers' repertoire. The results revealed that with an increase in L2 proficiency, the VOT values in L3 English approached those of Danish, the speakers' L2, whereas with higher L3 proficiency, the VOT values in L3 English were closer to those of English and/or Polish, resulting in lower VOT.

Taking everything into account, it can be stated that previous research clearly points to a number of tendencies. Lower L2 proficiency leads to less influence from the L2 on the L3, whereas greater proficiency in the L2 denotes more influence from this language on the L3. Conversely, with lower L3 proficiency, L3 is produced less accurately and the production is more accurate the greater there is proficiency in such language. Although some of these tendencies might to a certain degree be straightforward, they have an interesting outcome. . What can be observed is that each language tugs the other one towards its own values for the particular feature under analysis.

\section{Spectral properties of sibilants}

Fricatives have been analysed with regard to a number of acoustic parameters (e.g. Hughes \& Halle 1956; Strevens 1960; Jassem 1962) including "spectral properties of the friction noise, amplitude of the noise, duration of the noise, and spectral properties of the transition into and out of the surrounding vowels" (Reetz \& 
Jongman 2009:189). This study focuses only on the spectral properties of the Spanish sibilant because it has been claimed that sibilants, and particularly alveolar sibilants, have a clearer spectral shape in comparison to other fricatives because the air is obstructed by the teeth which gives them their characteristic sibilance (del Saz Caracuel 2013:56). Moreover, sibilants are characterised by a certain amount of higher frequency energy (Ladefoged 1975). In a cross-linguistic study of voiceless fricatives, Gordon, Barthmaier and Sands (2002) noticed a tendency for fronter tongue articulations to have higher gravity center values. Most speakers in the study produced an alveolar/s/ with the greatest noise above $5 \mathrm{kHz}$ regardless of the language. Dart $(1991,1998)$ shows that apical alveolars and laminal dentals have sharper peaks than laminal alveolars and apical dentals in French and English. What is more, the shape of /s/ may sometimes closely resemble that of /ç/. In this case, the two sounds can be differentiated by means of the overall greater noise of $/ \mathrm{s} /$, especially at higher frequencies where $/ \mathrm{s} /$ tends to plateau rather than show the steady decline characteristic of /ç/. Retroflexion is also associated with the lowering of spectral peaks (Gordon, Barthmaier \& Sands 2002), and Lindblad (1980) shows that in Swedish spectral shape rather than location of the primary spectral peak distinguishes $/ \mathrm{s} /$ from $/ / /$ ).

Spanish has an alveolar sibilant (Martínez Celdrán, Fernández Planas \& Carrera-Sabaté 2003) with a number of possible realizations (e.g. Salcedo 2010; Zampaulo 2013). The two most important pronunciations for the purpose of this study are: the lamino-alveolar sibilant (ese predorsal in Spanish) [s] and the apicoalveolar sibilant [S] (ese castellana). The former is produced with the tongue blade making light contact with the alveolar ridge. A groove is formed along the surface of the tongue through which air passes producing noisy sibilance (Whitley 2002). This realization is typical for Andalusia and Southern America Spanish and is rarely found across northern Spain. The latter sibilant is produced with the tip of the tongue approximating the alveolar ridge leaving a small round aperture for the air. The front part of the tongue is to some extent concave thus the sound is frequently labeled as retroflex (Macpherson 1975). This produces a spectral peak of lower frequency than the lamino-alveolar sibilant and may even be auditorily confused with $/ \delta /$ by non-native speakers of Spanish (Whitley 2002). This realization is the most common for all contexts except before a voiced consonant in Standard Castilian Spanish, but the contact point may be a little fronter towards the gums in the context of /i/ and /e/ (Navarro Tomás 1957:81). The alveolar fricative $/ \mathrm{s} /$ is also subject to an allophonic rule and is realized as a voiced fricative [z] before a voiced consonant, e.g. \{realismo\} is pronounced as [realizmo].

This study will take into consideration the four spectral moments: centre of gravity (M1), standard deviation (M2), skewness (M3) and kurtosis (M4). Initially proposed for stop differentiation (Forrest, Weismer, Milenkovic \& Dougall 1988), this analysis treats the fricative noise spectrum as a probability density distribution and calculates the statistical moments of the distribution (Jongman, Wayland \& Wong 2000). M1, or centroid frequency, is negatively correlated with the length of the oral cavity, thus a backer place of articulation will result in a lower M1 value. M2 shows variance from the centroid frequency 
whereas M3 stands for the overall spectral distribution and returns the energy difference above and below the centre of gravity. Finally, M4 measures the peakedness of the fricative energy distribution as compared to a normal distribution. In a recent study by Li, Edwards and Beckman (2009) M1 was shown to be a primary acoustic correlate to contrast $/ \mathrm{s} /$ and $/ \mathrm{g} /$ in English.

\section{Aim}

The particular goal of the study is to determine the influence of L2 and L3 level of proficiency and the interaction of the two factors on the production of the apicoalveolar sibilant in the L3. The research group consists of 25 speakers with different levels of proficiency in the two foreign languages. The parameters under analysis are spectral moments: M1, M2, M3 and M4.

\section{Method}

\subsection{Research group}

The study included 25 speakers, all of whom were Polish native speakers who additionally speak English and Spanish (L1 Polish, L2 English, L3 Spanish) at various levels of proficiency. There were 20 females and 5 males aged from 19 to $25(\mathrm{M}=22)$. Their age of onset of acquisition in the $\mathrm{L} 2$ varied from 3 to $18(\mathrm{M}=8)$, while the age of onset of acquisition in the $\mathrm{L} 3$ ranged from 3 to $20(\mathrm{M}=15)$.

All participants were 2nd and 3rd year students of Spanish philology at Adam Mickiewicz University in Poznań. During their studies they had 14 classes of Spanish, including grammar, phonetics, speaking and writing, and 2 classes of English per week with grammar, speaking, writing and elements of phonetics. They differed with respect to the level of proficiency in their L2 and L3, which was established by means of a final year exam in Spanish and in English. The exam consisted of four parts: speaking, writing, reading and use of Spanish/English. The level of proficiency taken into consideration in this study was the final score of all the exam parts in sum. The participants can be grouped into three levels of L2 proficiency corresponding to B1 $(n=7), B 2(n=10)$ and C1 $(\mathrm{n}=8)$ according to the Common European Framework of Reference and three levels of L3 proficiency corresponding to $\mathrm{B} 1(\mathrm{n}=6), \mathrm{B} 2(\mathrm{n}=9)$ and $\mathrm{C} 1(\mathrm{n}=10)$.

\subsection{Procedure}

Spectral moments of the Spanish apico-alveolar sibilant /s/ were measured in intervocalic position between vowels in two-syllable words (puso, paso, peso, poso, piso) with initial stress. The participants were asked to read the word in a carrier phrase (Digo otra vez.). All words were pronounced twice by each speaker which resulted in 250 tokens, of which 7 were discarded due to 
mispronunciations and other disruptions in the signal. In total, 243 tokens were analysed.

The recordings were made with the use of a RØDE N1 condenser microphone connected to a computer by means of a Focusrite Scarlett 2i2 2Gen audio interface in a sound-treated room at Adam Mickiewicz University. The spectrum was set at $18000 \mathrm{~Hz}$ (Figure 1.) (Barreiro Bilbao 2002) and a high-pass filter was applied to exclude frequencies below $800 \mathrm{~Hz}$ to avoid the influence of possible intervocalic voicing (e.g. Koenig, Shadle, Preston and Mosshammer 2013). Only the central $50 \%$ of the fricative was analysed to eliminate coarticulatory effects with the previous sound, especially the aforementioned influence of $/ \mathrm{i}, \mathrm{e} /$. The fricative segment was determined on the basis of onset and cessation of noise confirmed by the oscilloscope trace (Figure 2). The spectral moments were extracted by means of a PRAAT script (Elvira-Garcia 2014).
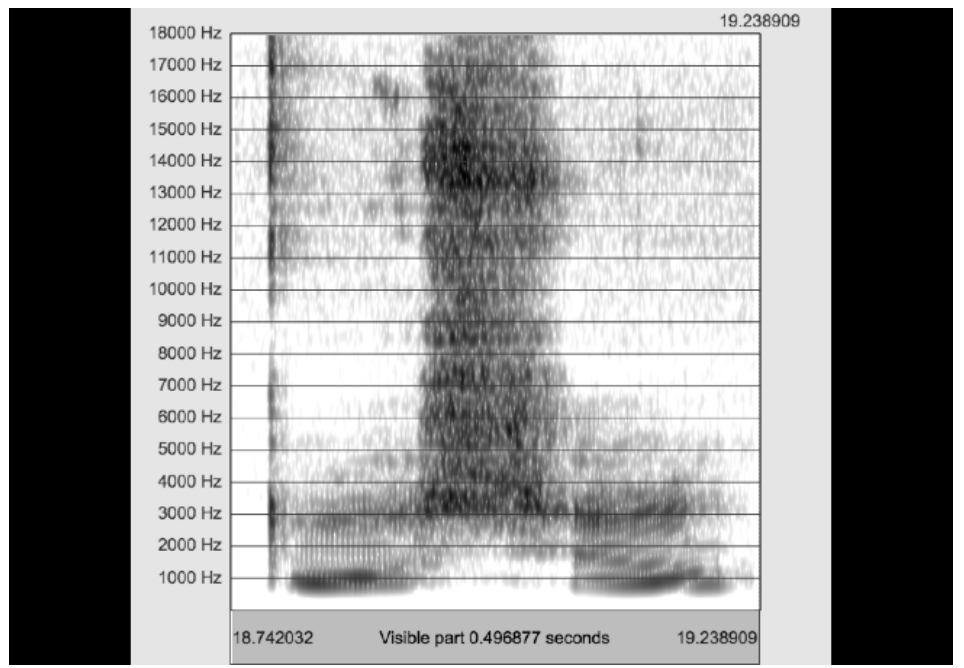

Figure 1. Spectrum settings 


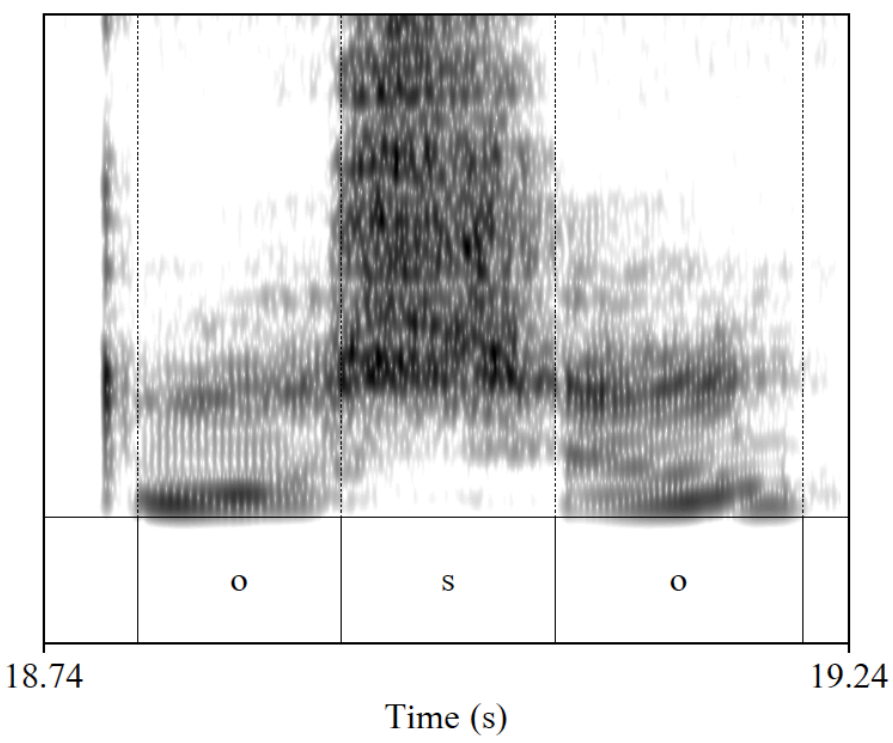

Figure 2. Annotation of the fricative segment

\subsection{Hypotheses}

The aim of the study is to determine the influence of L2 and L3 level of proficiency and the interaction of the two factors on the production of the sibilant in the L3. We expected an influence of both L2 and L3 level of proficiency. The starting point for the hypotheses is based on the tendency observed in previous studies that operates in the following way: the better one is in a language, the more the other language(s) resemble that language. Greater proficiency in L2 English will bring about an L3/s/ that is more English-like, whereas greater proficiency in L3 Spanish will results in an L3/s/ that is more Spanish-like. Bearing in mind the differences between the L3 Spanish /s/ and the L2 English /s/, the following hypotheses have been developed with regard to the four spectral moments of the L3 Spanish /s/ in the production of the research group.

As mentioned before, M1 stands for the centre of gravity and represents a centroid frequency. As M1 is negatively correlated with the length of the oral cavity, a backer place of articulation should give a lower M1 value, but we also expected the Spanish apico-alveolar/s/ to have a lower M1 than the English /s/ because of its slight retroflection and a lower spectral peak. The hypothesis for M1 is that greater L2 proficiency should result in a higher M1 in L3 Spanish /s/ whereas greater L3 proficiency would indicate a lower M1 in L3 Spanish /s/.

M2, the second spectral moment, represents standard deviation and means variance from the centroid frequency. Apico-alveolars should have a more compact frequency distribution which entails smaller standard deviation. We hypothesise that similarly as with centre of gravity, with an increase in L2 English 
proficiency, M2 may be higher whereas with an increase in L3 Spanish proficiency, M2 may be lower.

M3 represents skewness and refers to the overall spectral distribution. This is the energy difference above and below the centre of gravity. We expected a concentration of energy in the upper regions for the Spanish /s/ that translates to a higher M3. The hypothesis is that greater L2 proficiency should bring about a lower M3 in L3 Spanish whereas greater L3 proficiency should give a higher M3.

M4 represents kurtosis and refers to the peakedness of the fricative energy distribution as compared to a normal distribution. The apico-alveolar should have a sharper main spectral peak than lamino-alveolars (Dart 1991, 1992) so a higher M4. In terms of our study, a lower M4 should be observable with an increase in L2 proficiency whereas a higher M4 will be a consequence of greater L3 proficiency.

\section{Results}

A MANOVA was conducted in order to compare the main effects of L2 level of proficiency and L3 level of proficiency and the interaction effect between the two independent factors on the production of the L3 Spanish apico-alveolar sibilant measured by means of spectral moments. L2 level of proficiency and L3 level of proficiency were analysed for three levels $(1,2,3)$. The Bonferroni correction for multiple comparisons was applied to adjust the significance value.

Table 1 shows the descriptive statistics for mean values across levels of proficiency for M1 Cente of Gravity $(\mathrm{Hz})$. No difference is visible between the first and the second level of proficiency in L2LoP, whereas the mean is the highest for the third level of proficiency. In terms of L3LoP, the mean is the highest for the first level of proficiency and then decreases as the level of proficiency increases.

Table 1. Mean values across levels of proficiency for M1 Centre of Gravity (Hz)

\begin{tabular}{|lllll|}
\hline Factor & LoP & $\begin{array}{l}\text { Sample } \\
\text { size }\end{array}$ & $\begin{array}{l}\text { Mean } \\
(\mathrm{Hz})\end{array}$ & $\begin{array}{l}\text { Standard } \\
\text { Deviation }\end{array}$ \\
\hline L2LoP & 1 & 74 & 8115.3 & 2457.91 \\
L2LoP & 2 & 69 & 7858.5 & 2216.34 \\
L2LoP & 3 & 99 & 9448.7 & 1624.42 \\
L3LoP & 1 & 91 & 11661.6 & 2329.45 \\
L3LoP & 2 & 70 & 8628.7 & 2103.68 \\
L3LoP & 3 & 81 & 8258.3 & 1094.46 \\
\hline
\end{tabular}

As presented in Table 2, mean values across levels of proficiency in L2 and L3 for M2 Standard deviation (Hz) do not vary significantly. With regard to L2LoP, the mean value for M2 is the lowest for the first level of proficiency and the highest for the third one. Although only a slight difference can be observed 
between the three levels of L3 proficiency, still the third level of proficiency demonstrates the lowest value.

Table 2. Mean values across levels of proficiency for M2 Standard deviation (Hz)

\begin{tabular}{|lllll|}
\hline Factor & LoP & $\begin{array}{l}\text { Sample } \\
\text { size }\end{array}$ & Mean & $\begin{array}{l}\text { Standard } \\
\text { deviation }\end{array}$ \\
\hline L2LoP & 1 & 74 & 3150.5 & 95.89 \\
L2LoP & 2 & 69 & 3567.9 & 110.74 \\
L2LoP & 3 & 99 & 3810.9 & 102.62 \\
L3LoP & 1 & 91 & 3552.6 & 114.16 \\
L3LoP & 2 & 70 & 3576.6 & 103.74 \\
L3LoP & 3 & 81 & 3400.1 & 90.53 \\
\hline
\end{tabular}

Descriptive statistics for mean values across levels of proficiency for M3 Skewness are set out in Table 3. What can be observed is that for L2LoP, the mean is the highest for the greatest level of proficiency and the lowest for the second proficiency level. As for L3LoP, the mean is the lowest for the first level of proficiency and then becomes greater as the level of proficiency increases.

Table 3. Mean values across levels of proficiency for M3 Skewness

\begin{tabular}{|lllll|}
\hline Factor & LoP & $\begin{array}{l}\text { Sample } \\
\text { size }\end{array}$ & Mean & $\begin{array}{l}\text { Standard } \\
\text { Deviation }\end{array}$ \\
\hline L2LoP & 1 & 74 & 0.25 & 1.51 \\
L2LoP & 2 & 69 & 0.109 & 1.81 \\
L2LoP & 3 & 99 & 0.380 & 0.66 \\
L3LoP & 1 & 91 & -0.241 & 1.56 \\
L3LoP & 2 & 70 & 0.933 & 1.33 \\
L3LoP & 3 & 81 & 1.898 & 0.34 \\
\hline
\end{tabular}

Table 4 provides descriptive statistics for mean values across L2 and L3 levels of proficiency for M4 Kurtosis. As can be seen, the mean is the lowest for the second level of proficiency in the L2 and the highest for the first one, whilst for the L3LoP, the mean is the lowest for the first Level of proficiency and then increases in L3LoP.

Table 4. Mean values across levels of proficiency for M4 Kurtosis.

\begin{tabular}{|lllll|}
\hline Factor & LoP & $\begin{array}{l}\text { Sample } \\
\text { size }\end{array}$ & Mean & $\begin{array}{l}\text { Standard } \\
\text { Deviation }\end{array}$ \\
\hline L2LoP & 1 & 74 & 1.02 & 860.55 \\
L2LoP & 2 & 69 & 0.61 & 940.45 \\
L2LoP & 3 & 99 & 0.81 & 719.03 \\
L3LoP & 1 & 91 & -0.453 & 862.29
\end{tabular}




\begin{tabular}{|c|c|c|c|c|}
\hline L3LoP & 2 & $\begin{array}{l}70 \\
81\end{array}$ & 0.538 & 821.17 \\
\hline & 3 & 81 & & \\
\hline
\end{tabular}

In terms of standard deviation (SD) in all parameters under analysis, a tendency can be observed across levels of proficiency in the L2 and the L3. In all of the cases, except for M2, the SD values are the lowest for the highest proficiency levels in both L2LoP and L3LoP.

Multivariate test results (Table 5) point to significant main effects of L2LoP $(F=5,953, p<.01)$ and L3LoP $(F=10,349, p<.01)$ but also to a significant interaction effect of $\mathrm{L} 2 \mathrm{LoP} * \mathrm{~L} 3 \mathrm{LoP}(F=3,935, p<.01)$. The magnitude of each effect measured with partial eta squared allows us to conclude a medium size effect of L2LoP and the interaction effect and a large effect size of L3LoP.

Table 5. Multivariate test results.

\begin{tabular}{|llll|}
\hline Effect & $\mathrm{F}$ & Sig. & $\begin{array}{l}\text { Partial Eta } \\
\text { Squared }\end{array}$ \\
\hline Intercept & 9879.121 & .000 & 0.994 \\
L2LoP & 5.953 & .000 & 0.093 \\
L3LoP & 10.349 & .000 & 0.151 \\
L2LoP*L3LoP & 3.935 & .000 & 0.063 \\
\hline
\end{tabular}

The test of between-subjects effects and pairwise comparisons are visualised in Figure 3-6. Significant differences were found for M1 both in terms of L2LoP and L3LoP with the former showing higher mean M1 for the highest level of proficiency and the latter an opposite tendency with the lowest mean for the third level of proficiency (Figure 3). Further significant differences were found for L2LoP in terms of M2 (Figure 4) and L3LoP in terms of M4 (Figure 6). Both $\mathrm{M} 2$ and M4 showed a tendency to rise with a higher level of proficiency.
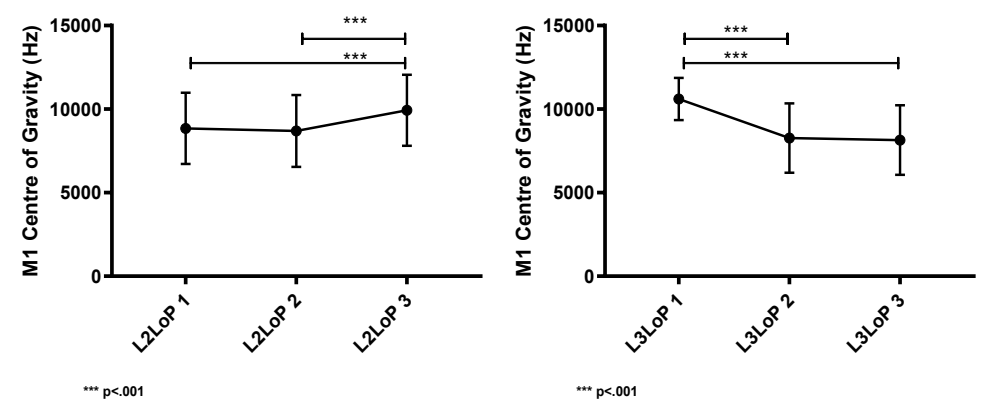

Figure 3. Pairwise comparisons for M1 Centre of Gravity 

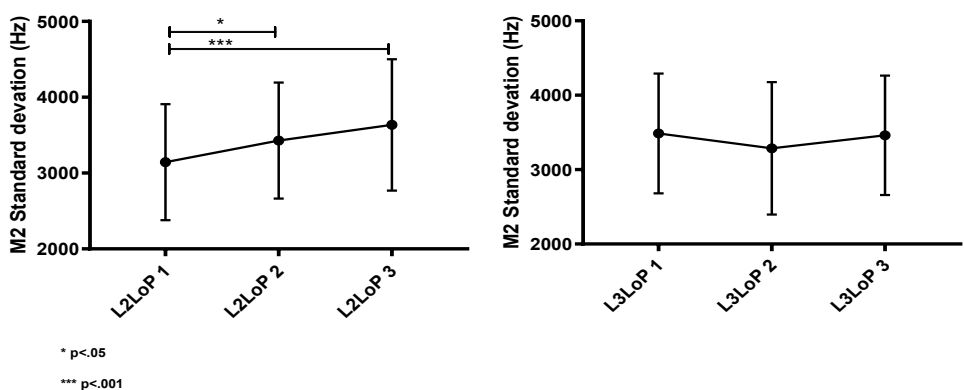

*** $p<.001$

Figure 4. Pairwise comparisons for M2 Standard deviation
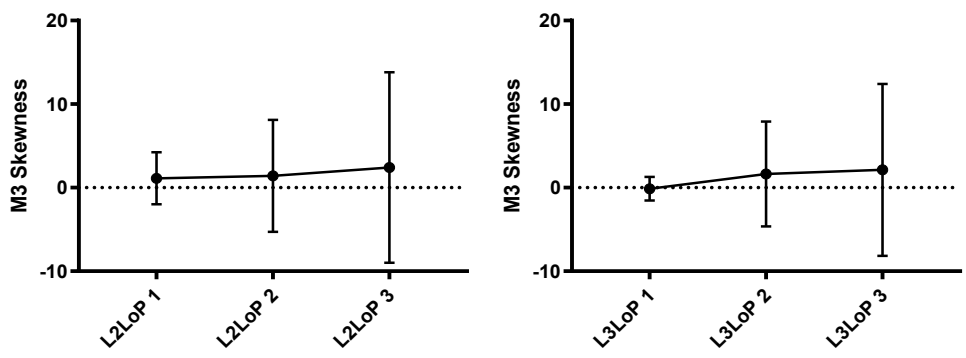

Figure 5. Pairwise comparisons for M3 Skewness
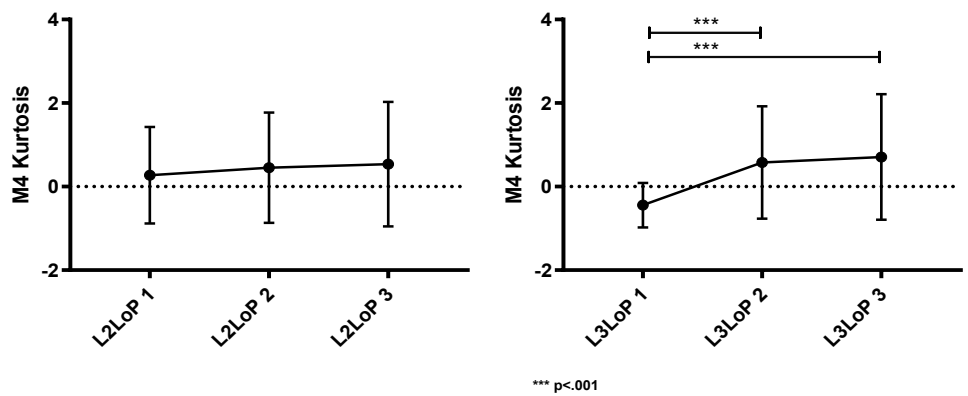

Figure 6. Pairwise comparisons for M4 Kurtosis

The interaction effect was particularly clear for M1 Centre of Gravity (at $\mathrm{p}<.001$; Figure 7) and M4 Kurtosis (at $p<.001$; Figure 9) and less so for M2 (at $p<.01$; Figure 8 ). A disordinal interaction effect of this type suggests that the 
variables of L2LoP and L3LoP together impact the value of the dependent variable and it may be misleading to analyse their effects separately. The effect of one of the variables is not constant but it differs depending on the value of the other effect. For the current data, this means that since L2 and L3 have a different value of M1 in their sibilants (the Spanish apico-alveolar and the English laminoalveolar) whenever the speaker has different proficiency levels in L2 and L3, the languages compete and pull the L3 Spanish M1 value towards its own values. However, when L2 and L3 are at the same level (in this case: 2) their mutual influence results in an in-between M1 of the L3 Spanish/s/ at a mean value of $9000 \mathrm{~Hz}$. The interaction effect works similarly for M2 and M4 for which the English and Spanish sibilant have different values and at different levels of proficiency the L2 and the L3 compete and pull the L3 Spanish M2 and M4 towards its own values. M4 Kurtosis differs only insofar as the point at which the mutual influence of L2LoP and L3LoP results in an in-between M4 value is at the third level of proficiency and not the second as is the case for M1 and M2. Only those speakers who have reached C1 level of proficiency in both L2 English and L3 Spanish show the in-between value of M4. The difference is explained by the fact that L2LoP as a main effect did not reach statistical significance for M4 and barely differs for the three levels of proficiency.

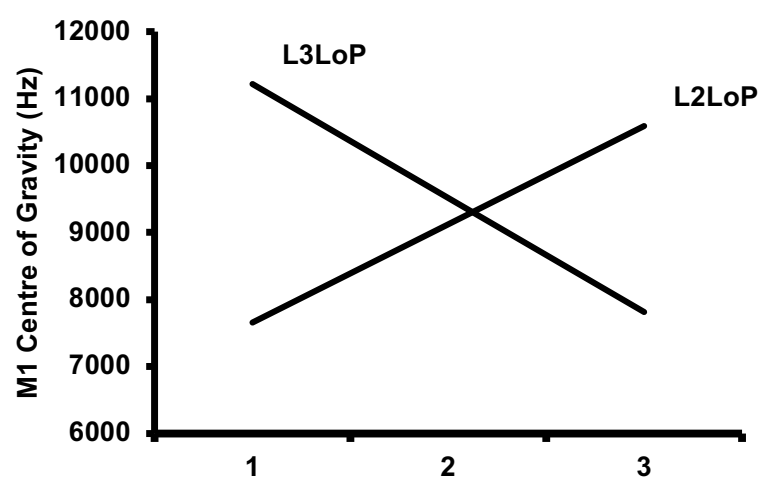

Figure 7. The interaction effect between L2LoP and L3LoP for M1 


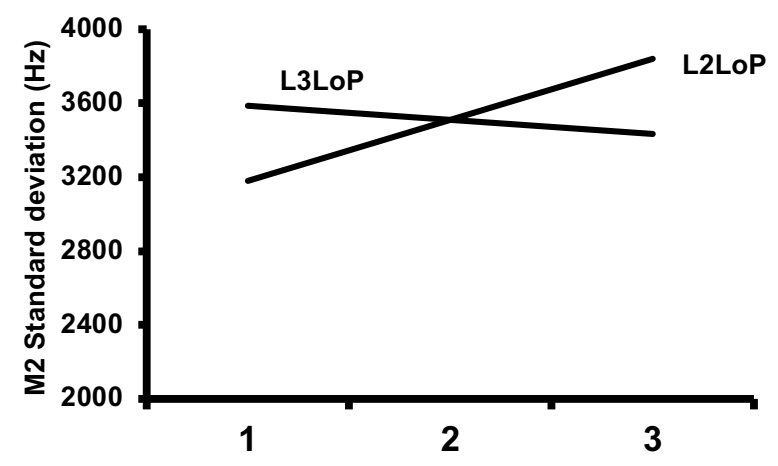

Figure 8. The interaction effect between $\mathrm{L} 2 \mathrm{LoP}$ and $\mathrm{L} 3 \mathrm{LoP}$ for $\mathrm{M} 2$

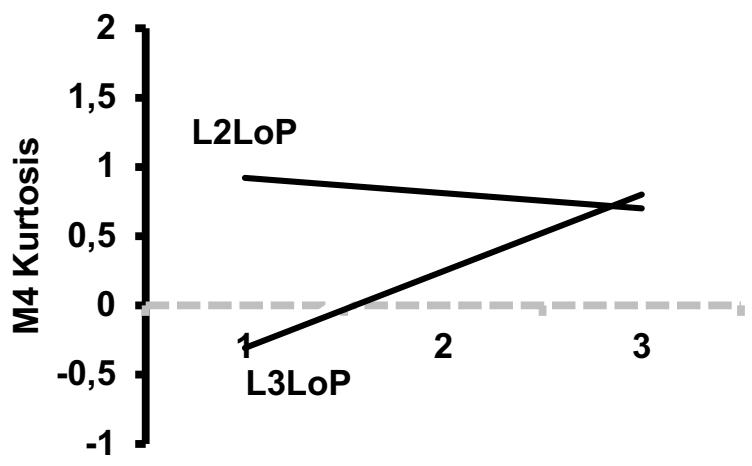

Figure 9. The interaction effect between L2LoP and L3LoP for M4

\section{Discussion}

The aim of the study was to determine the influence of L2 and L3 level of proficiency and the interaction of the two factors on the production of the apicoalveolar sibilant in the L3. The predictions for the behaviour of the four spectral moments in the L3 Spanish /s/ in this group of trilinguals were developed based on the tendency observed in earlier work that consists of the following: the better one is in a language, the more the other language(s) resemble that language. The results provide support for this. We observe a lower M1 among the participants with the lowest level of proficiency in L2 English and a higher M1 with the most advanced speakers of L2 English as the English sibilant has a higher M1 when compared to Spanish. An opposite tendency is observed for the influence of L3LoP since Spanish /s/ has a much lower M1. Participants with the lowest level of proficiency in Spanish have the greatest M1 value but the value is higher for the two higher levels of proficiency. In this regard, the current study results corroborate previous findings concerning the influence of level of proficiency in 
the L2 on the third language (e.g. Hammarberg 2001; Tremblay 2006) or the level of proficiency in the third language on the amount of influence from the L2 on the L3 (e.g. Wrembel 2010).

Also M2 and M4 show how one language pulls the other towards its own value with higher proficiency but in the case of these moments the tendency is observed only for one LoP at a time. As predicted, with greater L2LoP, M2 is higher whereas with greater L3LoP, M4 is higher. In fact, M4 and M2 are often correlated (Hardcastle, Laver and Gibbon 2012), thus some degree of concurrence in the results of M2 and M4 is expected.

The most interesting and telling part of the results is the interaction effect that reaches significance for M1, M2 and M4 and shows the particular interplay of the two factors under study. It turns out that it is not only the particular level of proficiency in one of the languages that shapes the L3 sibilant's spectral moments as it is simultaneously conditioned by the level of proficiency in the other language. When the level of proficiency in one of the languages is low, it allows the other language with a greater level of proficiency to exert influence on the values of M1, M2 and M4 in the L3 sibilant. However, when both language proficiencies are at the same level, the result is an intermediate value resultant of the L2 and the L3 sibilant spectral properties. This part of the results is a vital contribution to the research on the factor of level of proficiency in TLA. Since most studies focus on either L2 level of proficiency or L3 level of proficiency, the results are then described individually for each of the factors which could be misleading as it may be the interplay of the two that conditions the development of the L3.

\section{Conclusions}

The aim of the current study was to determine the influence of L2 and L3 level of proficiency ( $\mathrm{L} 2 \mathrm{oP}$ and $\mathrm{L} 3 \mathrm{oP}$ ) and the interaction of the two factors on the production of the L3 Spanish apico-alveolar sibilant in a group of L1 Polish, L2 English and L3 Spanish trilinguals with different levels of overall proficiency in the two foreign languages. The parameters of the sibilant under analysis were spectral moments: centre of gravity (M1), skewness (M2), kurtosis (M3) and standard deviation (M4) in intervocalic position in two-syllable words with initial stress. English has a lamino-alveolar and Spanish an apico-alveolar $/ \mathrm{s} /$ that should have different spectral properties measured by means of spectral moments. The predictions for the behaviour of the four moments in the L3 Spanish apico-alveolar $/ \mathrm{s} /$ in this group of trilinguals were developed based on the tendency observed in earlier work that operates in the following way: the better one is in a language, the more the other language(s) resemble that language. The results point to an influential role of both L2oP and L3oP but, most importantly, to the interaction effect of both the factors on the production of the L3 Spanish sibilant. Most robust data were observed for M1 Centre of Gravity which was conditioned by both L2LoP and L3LoP but the interaction effect was also visible for M2 and M4. When the level of proficiency in one of the languages was low, it allowed the other 
language with a higher level of proficiency to exert influence on the values of the spectral moments in the L3 sibilant. However, when both language proficiencies were at the same level, the result was an intermediate value resultant of the L2 and the L3 sibilant spectral properties. This kind of interplay of factors is the most important finding of the paper and furthers the understanding of how levels of proficiency in the second and the third language condition the developing L3 language.

\section{References}

Bardel, Camilla and Falk, Ylva. 2007. The role of the second language in third language acquisition: The case of Germanic syntax. Second Language Research, 23(4), 459-484. https://doi.org/10.1177/0267658307080557

Bardel, Camilla and Falk, Ylva. 2012. The L2 status factor and the declarative/procedural distinction. In J. Cabrelli Amaro, S. Flynn and J. Rothman (eds.), Third language acquisition in adulthood, 61-78. Amsterdam: John Benjamins. https://doi.org/10.1075/sibil.46.06bar

Barreiro Bilbao, Silvia Carmen. 2002 Speech perception in L2. Odisea, 2, 7-14.

Dart, Sarah. 1991. Articulatory and acoustic properties of apical and laminal articulations. Doctoral dissertation, UCLA [UCLA Working Papers in Phonetics 79].

Dart, Sarah. 1998. Comparing French and English coronal consonant articulation. Journal of Phonetics, 26, 71-94. https://doi.org/10.1006/jpho.1997.0060

Del Saz Caracuel, María. 2013. The effect of L1 dialect on the perception of phonetic variation in L2 morphological markers. Doctoral dissertation, Universidad de Sevilla.

Elvira-Garcia, Wendy. (2014). Zero-crossings-and-spectral-moments, v.1.3 [Praat script].

Flynn, Suzanne, Foley, Claire and Vinnitskaya, Inna. 2004. The Cumulative-Enhancement Model for language acquisition: Comparing adults' and children's patterns of development in first, second and third language acquisition of relative clauses. International Journal of Multilingualism, 1(1), 3-16. https://doi.org/10.1080/14790710408668175

Forrest, Karen, Weismer, Gary, Milenkovic, Paul and Dougall, Ronald N. 1988. Statistical analysis of word-initial voiceless obstruents: Preliminary data. Journal of the Acoustical Society of America, 84, 115-123. https://doi.org/10.1121/1.396977.

Garcia, Alison. 2013. The effects of L2 proficiency on L3 phonological acquisition: A preliminary test of the L2 proficiency hypothesis. In E. Voss, S. J. Tai and Z. Li (ed.), Selected Proceedings of the 2011 Second Language Research Forum: Converging Theory and Practice, (pp. 173-186).

Gordon, Matthew, Barthmaier, Paul. and Sands, Kathy. 2002. A cross-linguistic acoustic study of voiceless fricatives. Journal of the International Phonetic Association 32, 141-174. https://doi.org/10.1017/S0025100302001020

Gut, Ulrike. 2010. Cross-linguistic influence in L3 phonological acquisition. International Journal of Multilingualism, 7(1), 19-38.

Hammarberg, Björn. 2001. Roles of L1 and L2 in L3 production and acquisition. In J. Cenoz, B. Hufeisen and U. Jessner (eds.), Cross-linguistic influence in third language acquisition: Psycholinguistic perspectives, 21-41. Clevedon: Multilingual Matters. https://doi.org/10.21832/9781853595509-003

Hardcastle, William J., Laver, John and Gibbon, Fiona E. 2012. The Handbook of Phonetic Sciences, 2nd edition. New York: Wiley-Blackwell.

Hughes George W. and Halle, Morris. 1956. Spectral properties of fricative consonants. Journal of the Acoustical Society of America, 28, 303-310. https://doi.org/10.1121/1.1908271 
Jassem, Wiktor. (1962). Noise spectra of fricative consonants. In IV International Congress on Acoustics, Copenhagen G-17, also In Speech Communication Seminar, Stockholm B8, 1962.

Jongman, Allard, Wayland, Ratree. and Wong, Serena. 2000. Acoustic characteristics of English fricatives. Journal of the Acoustical Society of America, 108, 1252-1263. https://doi.org/10.1121/1.1288413

Kellerman, Eric. 1977. Towards a characterization of the strategy of transfer in second language learning. Interlanguage Studies Bulletin, 2(1), 58-145.

Koenig, Laura. L., Shadle, Christine H., Preston, Jonathan L. and Mooshammer, Christine R. 2013. Toward improved spectral measures of /s/: Results from adolescents. Journal of Speech, Language, and Hearing Research, 56, 1175-1189. https://doi.org/10.1044/10924388(2012/12-0038)

Ladefoged, Peter. 1975. A course in phonetics. New York: Harcourt Brace Jovanovich.

Li Fangfang, Edwards Jan and Beckman Mary E. 2009. Contrast and covert contrast: The phonetic development of voiceless sibilant fricatives in English and Japanese toddlers. Journal of Phonetics, 37(1), 111-124. https://doi.org/10.1016/j.wocn.2008.10.001

Lindblad, Per. 1980. Svenskans sje- och tje-ljud i ett allmänfonetiskt perspektiv. Travaux de l'Institut de Linguistique de Lund, 16. Lund: Gleerup.

Lipińska, Dorota. 2015. The influence of L2 status on L3 pronunciation. English Insights, 1, 6985.

Llama, Raquel, Cardoso, Walcir and Collins, Laura. 2010. The influence of language distance and language status on the acquisition of L3 phonology. International Journal of Multilingualism, 7(1), 39-57. https://doi.org/10.1080/14790710902972255

Macpherson Iain R. 1975. Spanish Phonology: descriptive and historical. Manchester: Manchester University Press.

Martínez Celdrán, Eeugenio, Fernández Planas, Ana and Carrera-Sabaté Josefina. 2003. Illustrations of the IPA: Castilian Spanish. Journal of the International Phonetic Association, 33(2), 255-259. https://doi.org/10.1017/S0025100303001373

Meisel, Jürgen M. 1983. Transfer as a second-language strategy. Language \& Communication, 3(1), 11-46. https://doi.org/10.1016/0271-5309(83)90018-6

Mykhaylyk, Roksolana, Mitrofanova, Natalia, Rodina, Yulia. and Westergaard, Marit. 2015. The Linguistic Proximity Model: The case of Verb-Second revisited. BUCLD 39 Proceedings. Somerville: Cascadilla Press.

Navarro Tomás, T. 1957. Manual de pronunciación española, $5^{\text {th }}$ edition. New York: Hafner Publishing Company.

Odlin, Terence. 1989. Language transfer: cross-linguistic influence in language learning. Cambridge: Cambridge University Press. https://doi.org/10.1017/CBO9781139524537

Reetz, Henning and Jongman, Allard. 2009. Phonetics: transcription, production, acoustics, and perception. Chichester: Blackwell.

Ringbom, Håkan. 1986. "Crosslinguistic influence and the foreign language learning process“. In: E. Kellerman, \& M. Sharwood Smith (eds..), Crosslinguistic Influence in Second Language Acquisition. New York: Pergamon Press, 150-162.

Rothman, Jason. 2010. On the typological economy of syntactic transfer: Word order and relative clause high/low attachment preference in L3 Brazilian Portuguese. International Review of Applied Linguistics in Language Teaching, 48(2/3), 245-273. https://doi.org/10.1515/iral.2010.011

Rothman, Jason. (2013). Linguistic and cognitive motivations for the Typological Primacy Model (TPM) of third language (L3) transfer: Timing of acquisition and proficiency considered. Bilingualism: Language and Cognition. https://doi.org/10.1017/S136672891300059X

Salcedo, Claudia S. 2010. The phonological system of Spanish. Revista de Lingüistica y Lenguas Aplicadas, 5, 195-209. https://doi.org/10.4995/rlyla.2010.769

Sánchez, Laura. (2014). An inquiry into the role of L3 proficiency on crosslinguistic influence in third language acquisition. Odisea : Revista de Estudios Ingleses, 15, 169-188.

Simon, Ellen, Escudero, Paola and Broersma, Mirjam. 2010. Learning minimally different words in a third language: L2 proficiency as a crucial predictor of accuracy in an L3 word 
learning task. In K. Dziubalska-Kołaczyk, M. Wrembela and M. Kul (ed.), New Sounds : Proceedings of the Sixth International Symposium on the Acquisition of Second Language Speech, 439-444.

Slabakova, Roumyana. 2016. The scalpel model of third language acquisition. International Journal of Bilingualism, 21(6), pp. 651-665. https://doi.org/10.1177/1367006916655413

Strevens, Peter. 1960. Spectra of fricative noise in human speech. Lang Speech, 3, 32-49. https://doi.org/10.1177/002383096000300105

Sypiańska, Jolanta. 2017. Cross-linguistic influence in bilinguals and multilinguals. Poznań: Wydawnictwo Naukowe UAM.

Tremblay, Marie-Claude. 2006. Cross-linguistic influence in third language acquisition: The role of L2 proficiency and L2 exposure. Cahier's Linguistiques d'Ottawa, 34, 109-119.

Westergaard, Marit, Mitrofanova, Natalia, Mykhaylyk, Roksolana and Rodina, Yulia. 2016. Crosslinguistic influence in the acquisition of a third language: The Linguistic Proximity Model. International Journal of Bilingualism, 21(6), 666 - 682. https://doi.org/10.1177/1367006916648859

Whitley, M. Stanley. 2002. Spanish/English Contrasts: A Course in Spanish Linguistics, 2nd edition. Washington: Georgetown University Press.

Williams, Sarah and Hammarberg, Björn. 1998. Language switches in L3 production: implications for a polyglot speaking model. Applied Linguistics, 19(3), 295-333. https://doi.org/10.1093/applin/19.3.295

Wrembel, Magdalena. 2010. L2-accented speech in L3 production. International Journal of Multilingualism, 7(1), 75-90. https://doi.org/10.1080/14790710902972263

Zampaulo, André. 2013. Sibilant Dissimilation in the History of Spanish: An InformationTheoretic Approach. In C. Howe et al. (eds.), Selected Proceedings of the 15th Hispanic Linguistics Symposium, 172-178. Somerville: Cascadilla Proceedings Project. 


\section{Appendix 1}

\section{Test of between-subject effects}

\begin{tabular}{|c|c|c|c|c|c|c|c|}
\hline Source & & $\begin{array}{l}\text { Type III Sum } \\
\text { of Squares }\end{array}$ & $\mathrm{df}$ & Mean Square & $\mathrm{F}$ & Sig. & $\begin{array}{l}\text { Partial } \\
\text { Eta } \\
\text { Squared }\end{array}$ \\
\hline \multirow{4}{*}{$\begin{array}{l}\text { Corrected } \\
\text { Model }\end{array}$} & M1 & 433614918,8 & 8 & 54201864,85 & 17,245 &, $000 * * *$ & 0,371 \\
\hline & M2 & 19341786,52 & 8 & 2417723,315 & 3,833 &, $000 * * *$ & 0,116 \\
\hline & M3 & 803,351 & 8 & 100,419 & 1,487 & 0,163 & 0,048 \\
\hline & M4 & 115,416 & 8 & 14,427 & 9,051 &, $000 * * *$ & 0,236 \\
\hline \multirow{4}{*}{ Intercept } & M1 & 14602215728 & 1 & 14602215728 & 4645,831 &, $000 * * *$ & 0,952 \\
\hline & M2 & 2185880624 & 1 & 2185880624 & 3465,482 &, $000 * * *$ & 0,937 \\
\hline & M3 & 132,219 & 1 & 132,219 & 1,957 & 0,163 & 0,008 \\
\hline & M4 & 10,759 & 1 & 10,759 & 6,75 &, $010^{*}$ & 0,028 \\
\hline \multirow{4}{*}{ L2LoP } & M1 & 17812253,79 & 2 & 8906126,896 & 7,834 & $.000^{* * *}$ & 0,024 \\
\hline & M2 & 14388494,66 & 2 & 7194247,33 & 11,406 &, $000 * * *$ & 0,089 \\
\hline & M3 & 5,244 & 2 & 2,622 & 0,039 & 0,962 & 0 \\
\hline & M4 & 2,033 & 2 & 1,016 & 0,638 & 0,529 & 0,005 \\
\hline \multirow{4}{*}{ L3LoP } & M1 & 233904302,8 & 2 & 116952151,4 & 37,209 &, $000 * * *$ & 0,241 \\
\hline & M2 & 1244629,82 & 2 & 622314,91 & 0,987 & 0,374 & 0,008 \\
\hline & M3 & 136,752 & 2 & 68,376 & 1,012 & 0,365 & 0,009 \\
\hline & M4 & 40,262 & 2 & 20,131 & 12,63 &, $000 * * *$ & 0,097 \\
\hline \multirow{4}{*}{$\begin{array}{l}\text { L2LoP * } \\
\text { L3LoP }\end{array}$} & M1 & 89813672,14 & 4 & 22453418,04 & 7,144 &, $000 * * *$ & 0,109 \\
\hline & M2 & 8925029,293 & 4 & 2231257,323 & 3,537 &, $008^{* *}$ & 0,057 \\
\hline & M3 & 407,796 & 4 & 101,949 & 1,509 & 0,2 & 0,025 \\
\hline & M4 & 36,734 & 4 & 9,183 & 5,761 &, $000 * * *$ & 0,09 \\
\hline \multirow{4}{*}{ Error } & M1 & 735480597 & 234 & 3143079,474 & & & \\
\hline & M2 & 147597370,5 & 234 & 630757,993 & & & \\
\hline & M3 & 15807,031 & 234 & 67,551 & & & \\
\hline & M4 & 372,986 & 234 & 1,594 & & & \\
\hline \multirow{4}{*}{ Total } & M1 & 19140901659 & 243 & & & & \\
\hline & M2 & 3020336357 & 243 & & & & \\
\hline & M3 & 17337,103 & 243 & & & & \\
\hline & M4 & 545,682 & 243 & & & & \\
\hline \multirow{4}{*}{$\begin{array}{l}\text { Corrected } \\
\text { Total }\end{array}$} & M1 & 1169095516 & 242 & & & & \\
\hline & M2 & 166939157 & 242 & & & & \\
\hline & M3 & 16610,381 & 242 & & & & \\
\hline & M4 & 488,401 & 242 & & & & \\
\hline
\end{tabular}

